\title{
The Application of Certain Strategies to Legal Translation
}

\author{
Jun Song * \\ School of Foreign Languages, Southwest University for Nationalities, Chengdu 610041, China \\ 1164859981@qq.com
}

Keywords: Skopos, legal translation, undertranslation, overtranslation, mistranslation

\begin{abstract}
This paper carries out a comparative study on the two English versions of SLPRC, and makes an analysis of some problems found in the two English versions. By dealing with some practical legal translation problems, this study attempts to gain some insights into the translation of legal texts and puts forward some practicable techniques in translating legal texts.
\end{abstract}

\section{Introduction}

One of the main tasks of translation theorists is to identify the criteria to aid translators in selecting an adequate translation strategy. This presupposes, of course, that the translator is vested with the authority to make such decisions. Since the traditional view that the translator's primary task is to transfer the meaning of the source text has been challenged, the translator is thus released from his / her commitment to reproduce the source text and has become a text producer who creates a new text by selecting a translation strategy on the basis of the communicative factors of reception in each situation. At first it was believed that translation strategy is determined primarily by the type of audience to whom the target text is directed. For example, the translation of a financial report for laymen differs considerably from a translation of the same text for financial experts. Thereafter, theorists shifted the main emphasis to the communicative function or purpose of a translation.

In view of the special nature of legally binding texts, it is agreed that substance must always prevail over form in legal translation. In traditional translation, where the translator is expected to reconstruct the form and substance of the source text in the target language, the function of the target text is always the same as that of the source text. Vermeer's Skopos theory departs from tradition by recognizing translations in which the function of the target text differs from that of the source text. The functional approach presumes that the same text can be translated in different ways depending on the communicative function of the target text [1]. Guided by loyalty to the Skopos, the translator is free to produce a new text that differs considerably from the source text in both form and substance. However, as responsible decision-makers, legal translators must know exactly how far they can stretch their limited freedom and still respect the restraints of their profession. Since legal texts are subject to legal criteria, it follows that a theory for the translation of legal texts must take account of legal considerations. In the same token, it cannot disregard basic issues of translation theory.

\section{A Comparative Study on the two English versions of SLPRC}

\subsection{Problems found in the two English versions of SLPRC}

A comparative study on the two English versions of the Securities Law of the People's Republic of China (hereinafter referred to as SLPRC) is offered to exemplify the strategies of specific translation problems. The two English versions are published respectively by Foreign Language Press (hereinafter referred to as V1) [2] and Publishing House of Law (hereinafter referred to as V2) [3]. After studying them, we classified the problems found in these two versions into three types: undertranslation, overtranslation, and mistranslation.

\subsubsection{Undertranslation}

In translation and in legal translation, in particular, it is necessary for translators to strive to convey all the information in the original text into the target language. Thereby, particular attention should be 
paid to avoid the omission of words or phrases, which would cause the loss of information in the target text.

Undertranslation takes place when the translated version represents an overly simplified version of the original text. It mainly results, according to the author, from translators' failure in grasping the actual meaning of the original or lack of a good command of the target language.

Example 1:

V1:A securities company which fails to go into operation for more than three months or stops doing business by itself for more than three months shall have its business license revoked by the company registration organ.

V2: If, after its establishment, a securities company fails to commence business without justifiable reason or, after having commenced business, it suspends business on its own for a period of not less than three months running, its corporate business license shall be revoked by the company registration organ.

The translator of V1 leaves some key words untranslated and thus fails to convey important quantitative information. According to the Statutory Interpretation of The Securities Law of the People's Republic of China(hereinafter referred to briefly as the Statutory Interpretation)elaborated by the drafting group of SLPRC, with justifiable reason, a securities company's business license may not be revoked by the company registration organ if it fails to commence business. However, the translator leaves an important word untranslated in V1 and such an undertranslation may mislead the readers to understand that a securities company's business license shall be revoked regardless of the situation. As such, the recipients of the translated text may misunderstand the real intent of the drafter of legislation.

\section{Example 2:}

V1: When underwriting securities, securities companies shall examine the truthfulness, accuracy and integrity of the collected documents for public issuance. Those who have been found guilty of falsifying records, or making culpable omissions in documents should not engage in securities sales. If they have sold securities, they must immediately cease selling and adopt measures of corrections.

V2: To underwrite securities, a securities company shall examine the truthfulness, accuracy and completeness of the public offer documents. If it finds any falsehoods, misleading statements or major omissions in such documents, it may not carry out the sales activities. If it has already begun to sell the securities, it shall immediately discontinue the sales activities and adopt remedial measures.

This article stipulates the examination of the public offer documents and the termination of sales activities under certain conditions. The discovery of "misleading statements" is one of the situations in which the sales activities should be terminated. However, the translator of V1 leaves out this important word, and thus undesirably exempts securities companies who find a misleading statement in the public offer documents from the obligation provided for in this article. V2 is an adequate rendition of the original text.

\subsubsection{Overtranslation}

Since adequacy in translation is measured for the degree of equivalence between the meaning of the original message and the meaning of the translated one, translators are thus required and duly expected to pay close attention to all contextual and situational factors underlying the original and the translated text.

text in translating. This refers to translators' arbitrary addition of any information not implicated in the original text. Translators should be on guard against overtranslation when striving to convey the exact meaning of the original. That is to say, any interpretation should be strictly kept within the confines of the original and translators should not add unnecessary information to the original at will. Example 3:

V1:(2) Changes in the company's major investment operations and important decisions concerning purchasing assets.

V2: (2) a decision made by the company concerning a major investment or major asset purchase. 
The underlined part in V1 is not implicated in the original text, and there is no corresponding part of "changes" in the original. The translator's arbitrary addition of "changes" may mislead the readers. Since the required information has been conveyed in V1, the unnecessary part should be deleted. V2 is an adequate rendition of the original text.

Example 4:

V1: The approved procedures shall be open to the public, making corruption be subject to supervision.

V2: The verification procedures shall be made public and shall be subject to supervision according to law.

The translator of V1 adds "corruption" though its meaning is not implicated in the original text. According to the Statutory Interpretation, this article stipulates the requirements for the securities regulatory authority under the State Council, the persons involved in the verification of an application for issuance of shares, and the department authorized by the State Council. In terms of legal translator, his main task is to transfer the meaning of the original text in the target language rather than adding any unnecessary information to the original at will. V1 only gives the readers a false impression that corruption is part of the verification procedures and that the purpose of the opening of the verification procedure is to make it subject to supervision. V2 is an adequate rendition of the original text as compared with V1.

\subsubsection{Mistranslation}

As is known, the correct understanding of the original text is the prerequisite condition for a successful translation. However, the translators sometimes fail to grasp the exact meaning of the original text. Since legal translating demands a precision that may not be so strictly required in other types of translation, a correct understanding of the source text is of the utmost importance for legal translators.

Example 5:

V1: Cases which constitute crimes shall be investigated for criminal liability in accordance with the law

V2: If the offense constitutes a crime, criminal liability shall be pursued according to law.

"Zhui jiu" is translated into "investigate" in V1 and "pursue" in V2 respectively. Let's look up the term "criminal investigation" in the Dictionary of Law, and we can find it is interpreted as "an investigation which police officers or other persons have a duty to conduct with a view to it being ascertained whether a person should be charged with an offence, or whether a person charged with an offence is guilty of it. Where a criminal investigation is conducted, all reasonable steps are taken for the purpose of the investigation and all reasonable lines of inquiry are pursued." [4] As can be seen from the above definition, "investigate" is the initial stage of "Zhui jiu". Therefore, the word "investigation" in V1 will make a false impression on readers that the offender who committed a crime would receive a mere investigation into the facts but not the prosecution of criminal liability. As to "pursue" in V2, it is interpreted in the Oxford Advanced Learner's English-Chinese Dictionary as "(continue to) be occupied or busy with (sth); go on with" [5] and "Ji $x u$ " in Chinese. Therefore, "pursue" is neither the counterpart of "Zhui Jiu" nor a word which can be collocated with "criminal liability". In the writer's opinion, "Zhui Jiu" here can be rendered into "prosecute", meaning "the instituting of criminal proceedings involving an accused person in the courts" [4]. Therefore, the author offers the following version for this article:" If the offense constitutes a crime, criminal liability shall be prosecuted according to law."

\subsection{The Application of Certain Strategies}

As is shown above, the two translational actions that are presented are about the translation of one prescriptive legal text. The English version of SLPRC published by Foreign Language Press is chiefly intended for meeting the needs of the people both at home and abroad to get a comprehensive and precise knowledge of China's laws. The English version of SLPRC published by Publishing House of Law, which is primarily addressed to legal professionals, overseas investors, lawyers, etc, is intended 
for providing precise information of laws and policies for the citizen to consult. The English versions of Chinese laws and regulations are chiefly intended for popularizing the Chinese government's economic and political policies, so any deviation from the meaning of original texts will lead to a misunderstanding of, and even disputes on laws. Therefore, the Skopos of the two translational actions are source-text oriented and accordingly the target text's function is the metatextual one. Furthermore, in a legal sense, a metatextual target text is the best way to keep intact the prescriptive nature of the original statutes and a way for the translator to show his respect for the authority of law. Based on a functional approach, a documentary translation has a metatextual function, whereas an instrumental translation has a (an) referential / expressive / appellative / phatic function and / or subfunctions [6]. Accordingly, two translational actions presented above should take a documentary translation strategy, as shown in Fig. 1.

Table 1 Documentary translations [6]

\begin{tabular}{|c|c|c|c|c|}
\hline $\begin{array}{c}\text { Function of } \\
\text { translation }\end{array}$ & \multicolumn{4}{|c|}{$\begin{array}{c}\text { document of source-culture communicative interaction } \\
\text { for target-culture readership }\end{array}$} \\
\hline $\begin{array}{c}\text { Function of target } \\
\text { text }\end{array}$ & \multicolumn{4}{|c|}{ Metatextual function } \\
\hline Type of translation & $\begin{array}{c}\text { interlineal } \\
\text { translation }\end{array}$ & $\begin{array}{c}\text { literal } \\
\text { translation }\end{array}$ & $\begin{array}{c}\text { philological } \\
\text { translation }\end{array}$ & exoticizing translation \\
\hline Form of translation & $\begin{array}{c}\text { system } \\
\text { of SL form } \\
\text { translation }\end{array}$ & $\begin{array}{c}\text { reproduction of ST } \\
\text { form +content }\end{array}$ & $\begin{array}{c}\text { reproduction of ST form, } \\
\text { content + situation }\end{array}$ \\
\hline $\begin{array}{c}\text { Focus of translation } \\
\text { process }\end{array}$ & $\begin{array}{c}\text { structures of SL } \\
\text { lexis }+ \text { syntax }\end{array}$ & $\begin{array}{c}\text { lexical units } \\
\text { of source text }\end{array}$ & $\begin{array}{c}\text { syntactical units of } \\
\text { source text }\end{array}$ & textual units of source text \\
\hline
\end{tabular}

\section{Summary}

As can be seen above, function does play a role in legal translation; however, it is only one of the criteria to be taken into account when determining a translation strategy. We should not ignore the fact that legal texts are subject to legal rules governing their usage in the mechanism of the law. When selecting a translation strategy for legal texts, legal considerations must prevail.

\section{Acknowledgements}

This work is supported by the Fundamental Research Funds for the Central Universities, Southwest University for Nationalities (No. 2015SZYQN54).

\section{References}

[1]. Šarčević Susan. New Approach to Legal Translation. The Hague: Kluwer Law International, 1997, p.18.

[2]. Securities Law of the People's Republic of China. Foreign Language Press, 2001, p9-24.

[3]. Securities Law of the People's Republic of China. Publishing House of Law, 2002, p15-33.

[4]. L.B.Curzon. Dictionary of Law (Sixth Edition). Law Press, 2003, p111-338.

[5]. Oxford Advanced Learner's English-Chinese Dictionary (Extended fourth edition). Oxford University Press, 2002, p1206.

[6]. Nord, Christiane. Translating as a Purposeful Activity.Shanghai: Shanghai Foreign Language Education Press, 2001, p13-51. 